\title{
DRIVING BY THE SEAT OF YOUR PANTS! A MULTISENSORY APPROACH TO CAPTURING DRIVER ATTENTION
}

\author{
Charles Spence \\ Toyota Keynote Luncheon Lecture
}

The increasing availability of complex in-vehicle technologies means that 'driver inattention' constitutes one of the leading causes of car accidents. The question therefore arises as to how best to alert 'distracted' drivers to potential road dangers. The latest laboratory and simulatorbased studies from the Crossmodal Research Laboratory in Oxford detailing a novel brain-based approach to the design of auditory, tactile, and multisensory warnings signals. The talk will highlight research demonstrating the potential for improving driver behavior in potentially dangerous situations and so reducing the incidence of road traffic crashes that such multisensory warning signals offer. Results of recent studies showing that multisensory stimuli can capture the attention of the driver in the simulator (and the average participant in the psychology laboratory) far more effectively than unisensory stimuli will also be described. The importance of spatial colocation in multisensory warning signal design will also be discussed, as will new evidence regarding the potentially beneficial effects of presenting warning signals in near-rear peripersonal space (i.e., from the headrest) on drivers' head-turning responses.

\section{REFERENCES}

Ho, C., \& Spence, C. (2008). The multisensory driver: Implications for ergonomic car interface design. Aldershot: Ashgate Publishing.

Ho, C., \& Spence, C. (2009). Using peripersonal warning signals to orient a driver's gaze. Human Factors, 51, 539-556.

Professor Charles Spence is the head of the Crossmodal Research Laboratory based at the Department of Experimental Psychology, Oxford University in England. He is interested in how people perceive the world around them. In particular, how our brains manage to process the information from each of our different senses (such as smell, taste, sight, hearing, and touch) to form the extraordinarily rich multisensory experiences that fill our daily lives. His research focuses on how a better understanding of the human mind will lead to the better design of multisensory foods, products, interfaces, and environments in the future. His research calls for a radical new way of examining and understanding the senses that have major implications for the way in which we design everything from household products to mobile phones, and from the food we eat to the places in which we work and live. Charles is currently a consultant for a number of multinational companies advising on various aspects of multisensory design, packaging, and branding. He has also conducted research on human-computer interaction issues on the Crew Work Station on the European Space Shuttle, and currently works on problems associated with the design of foods that maximally stimulate the senses, and with the effect of the indoor environment on mood, well-being, and performance. He has published more than 250 articles in top-flight scientific journals over the last decade, and has been awarded the $10^{\text {th }}$ Experimental Psychology Society Prize, the British Psychology Society: Cognitive Section Award, the Paul Bertelson Award, recognizing him as the young European Cognitive Psychologist of the Year, and, most recently, the prestigious Friedrich Wilhelm Bessel Research Award from the Alexander von Humboldt Foundation in Germany. 